\title{
The Influence of Gangue Particle size and Gangue Feeding Rate on Safety and Service Life of the Suspended Buffer's Spring
}

https://doi.org/10.1515/geo-2019-0051

Received Oct 11, 2018; accepted Dec 22, 2018

\begin{abstract}
To address the problems of the suspended buffer spring's safety and service life, we introduce the basic operating principles and structure parameters of the suspended buffer; followed by establishing a new numerical model of the buffer spring vibration using Femap software. The vibration characteristics of the spring form the basis for spring safety check and service life prediction. Therefore, the principles influencing the gangue particle size and feeding rate on the vibration characteristics of the buffer spring were analyzed. The results have indicated that the vibration frequency, axial pressure peak and the maximum and minimum axial pressure within the periodic vibration had power relations with gangue particle size $D$, while they had linear relations with the gangue feeding rate $v$ except for the vibration frequency that had nothing to do with the feeding rate. According to the ultimate axial pressure of the spring, the relations between the shear pressure and tensile strength as well as the vibration characteristics, the spring's safety check formula and service life formula were obtained. Based on the backfilling parameters of the working face in Dongping Coal Mine, the crushed gangue particle size and spring service life were determined. Based on the engineering practice in Dongping Coal Mine, the spring service life was obtained. And the fatigue fracture of the spring was also analyzed.
\end{abstract}

Keywords: buffer spring, safety, service life, gangue particle size, gangue feeding rate, impact

\footnotetext{
*Corresponding Author: Shuai Guo: State Key Laboratory for GeoMechanics and Deep Underground Engineering, China University of Mining and Technology, Xuzhou 221116, China; Email: cumtct402@163.com; Tel.: +86-1871-1015-600

Yang Tai, Baifu An: School of Mines, China University of Mining and Technology, Xuzhou 221116, China; Key Laboratory of Deep Coal Resource Mining, China University of Mining and Technology, Xuzhou 221116, China
}

¿ Open Access. (c) 2019 Y. Tai et al., published by De Gruyter. (cc) BY License

\section{Introduction}

The fully-mechanized coal mining with solid backfilling is one of the methods to recover the coal resources under buildings, water bodies and railways [1]. The gangue backfilling could not only reduce backfilling costs to a great extent, but also could solve environmental pollution issues caused by the gangues, which are often considered to be the worthless rock or vein matter in which valuable metals or minerals occur. This is the reason why gangues are used as backfilling materials [2, 3]. However, the safe and efficient transport of gangue to the underground excavated areas, especially the coal mines, has been discussed recently [4]. As shown in Figure 1, after many years of research, Zhang et al. designed the suspended buffer to solve buffering problems of gangues [5].

Main function of the suspended buffer is to slow down the fast moving gangues from surface to underground during their transportation. This significantly reduces the chances of any damage caused due to impact of speeding gangue on the surface underneath [6]. It has been noticed earlier that the buffer's ultimate loading capacity and working hours are important performance indicators for

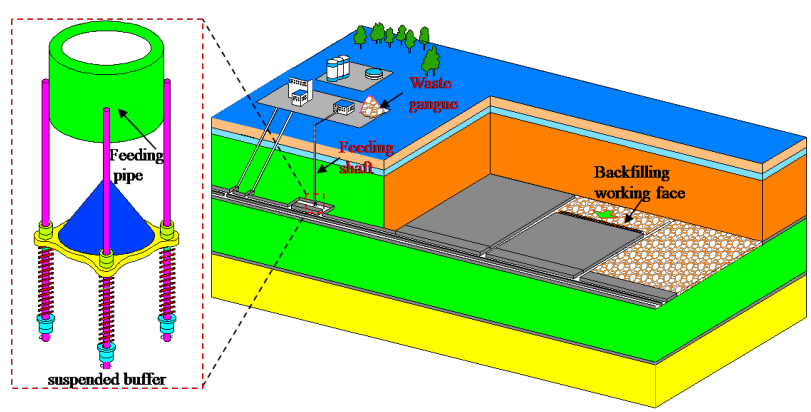

Figure 1: Gangue backfilling mining system and suspended buffer.

Fu Ju: State Key Laboratory for GeoMechanics and Deep Underground Engineering, China University of Mining and Technology, Xuzhou 221116, China 


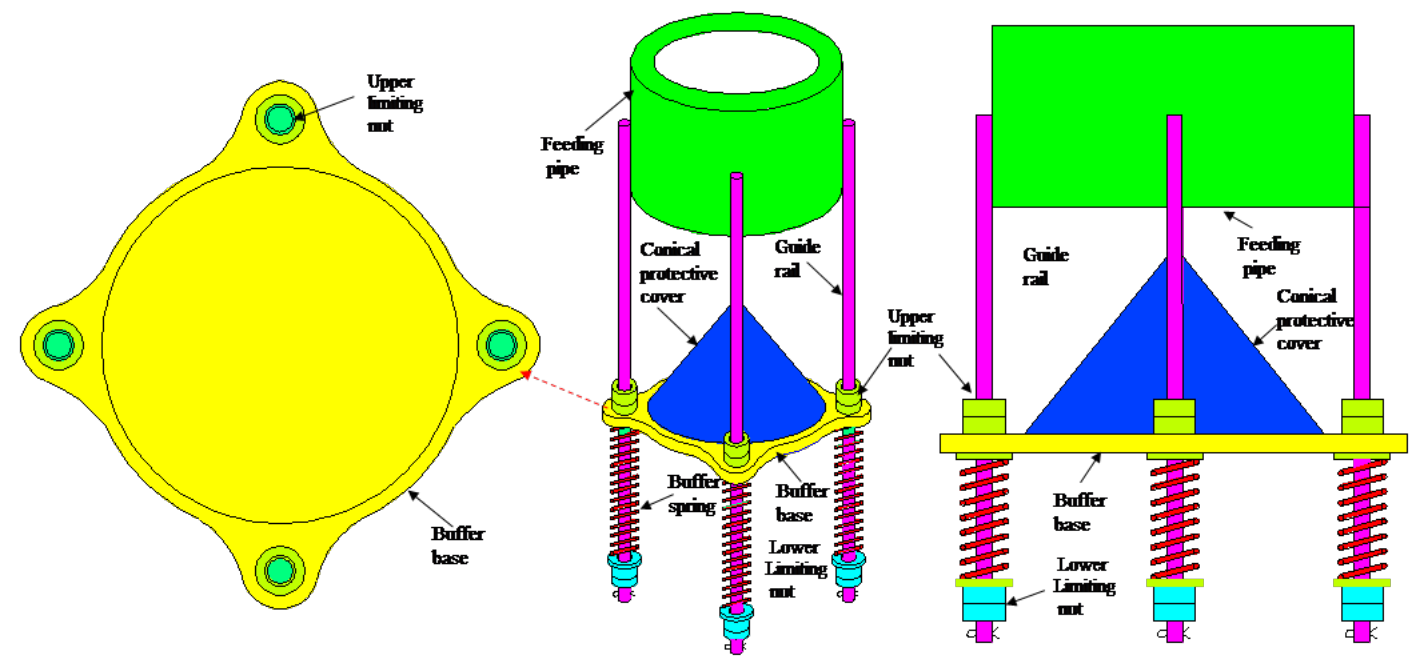

Figure 2: Main structural components of the suspended buffer.

the suspended buffer $[7,8]$. This has a direct consequence to the safety and service life of the buffer spring $[9,10]$; wherein service life refers to the fatigue failure time under periodic cyclic loading. On the other hand, the safety of the spring is related to the maximum axial pressure and the axial pressure peak values. In this paper we present the results of our study conducted for checking the safety and predicting the service life of the spring.

There are two ways of improving spring safety: (i) either the ultimate axial pressure of the spring could be increased by increasing the strength of spring materials. As a consequence of continuous improvement of material composition and processing technologies, the material strength of the spring gradually increased from $900 \mathrm{MPa}$ to more than $2000 \mathrm{MPa}$ [11, 12]. (ii) or by adjusting the spring's geometric parameters [10]. In terms of the fatigue failure of the spring, many experiments and applications had proved that the failure of helical spring was from inside to outside in a 45 degree direction along the inner surface under the actions of the cyclic loads [13]. The calculation method of the spring fatigue was put forward according to the cumulative damage theory [14, 15]. The smaller the surface roughness of spring materials, the smaller the stress concentration and the higher the fatigue strength. As the surface roughness increased, the fatigue limit would decrease [10].

Earlier, Liu et al. [5] studied the buffer's vibration response characteristics and structural stability, and optimized the feeding technology of gangue particles. Subsequently, Ju et al. [16] used the theoretical analysis method to study the elastic collision and plastic collision characteristics of gangues and conical buffer in a collision period.
Then the vibration equations of the buffer spring and vibration deflection equations of the support beam were established during the collision process.

The above-mentioned researches have focused on the spring's ultimate axial pressure, fatigue failure and buffer's vibration characteristics. There haven't been any significant numbers of in depth studies on the safety and service life of the suspended buffer spring; notwithstanding the fact that such information could provide theoretical basis for the safety judgement and service life prediction of a buffer spring. This paper is a step forward in this direction. Here we introduce the operating principles of the suspended buffer and structure parameters of the spring. Then we provide the numerical calculation method used to analyze the influence laws of gangue particle size and feeding rate on the safety and service life of the buffer spring. Finally, it was determined that the service life of the spring according to the gangue feeding rate of the Dongping Coal Mine.

\section{Operating principles of the suspended buffer and spring structure parameters}

\subsection{Operating principles}

As shown in Figure 2, the suspended buffer is mainly composed of a buffer mechanism and a limiting mechanism. The buffer mechanism includes a conical protective cover, a buffer base and buffer springs. The limiting mechanism 
consists of the upper limiting nuts, the lower limiting nuts and guide rails. The conical protective cover is fixed on the buffer base. The upper end of the buffer spring is connected with the buffer base, while the lower end is fixed on the lower limiting nut. The upper and lower limiting nuts are fixed with the buffer base and guide rails, respectively. The upper end of the guide rails is welded and fixed on the outer wall of the feeding pipe. The gangue particles are put into the buffer device through the feeding pipe. After the buffering of the conical protective cover, the gangue will be finally scattered in the storage silo with lower velocity. The buffer mechanism could achieve repeated buffering and recovery under the action of the buffer spring.

\subsection{Buffer spring}

The buffer spring is one of the key components of the suspended buffer. As shown in Figure 2, the buffer spring, located between the buffer and limiting nuts, is a kind of buffer device. It could not only store and release energy, but also could alleviate the impact and reduce the vibrations. The compression coil spring is most widespread among various types of springs. It is easy to manufacture and has compact structure, high energy absorption efficiency and zero friction. Therefore, it was taken as the damping component. To improve the strength of spring materials, the 60Si2CrVAT chromium-vanadium steel was adopted. Compared with 60Si2Mn steel, it has higher yield and tensile strength and larger anti-torsion and anti-shear ability [17]. As shown in Figure 3, the buffer spring had an outer diameter of $250 \mathrm{~mm}$, the pitch diameter of $200 \mathrm{~mm}$ and the inner diameter of $150 \mathrm{~mm}$. The material diameter was $50 \mathrm{~mm}$. The stiffness of the spring was $3.8 \times 10^{5} \mathrm{~N} / \mathrm{m}$. The effective turns were 20.

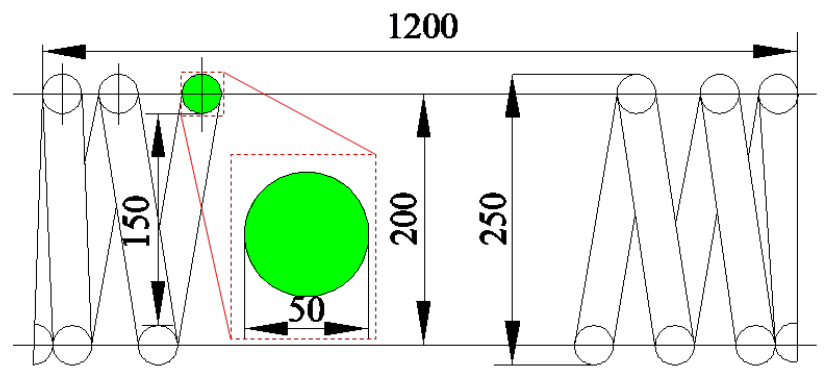

Figure 3: Parameters of the spring.

\section{The analysis of buffer spring's vibration characteristics}

The vibration characteristics of the buffer spring are the basis for evaluating its safety and predicting its service life. The gangue particle size and gangue feeding rate are core factors that affect vibration characteristics of the spring, so their influence laws on vibration characteristics of the spring should be analyzed. The out-of- pipe speed of the gangue particles was large and couldn't be obtained in the laboratory. Moreover, the physical simulation model was difficult to constrain the properties of the gangue and air. Therefore, the numerical simulation method was adopted in this paper. In the simulation, out-of- pipe speed of the gangue particles was obtained. Then the numerical simulation scheme was determined. Finally, the Femap software was used to establish the vibration model of the suspended buffer spring. The influencing factors of vibration characteristic of spring were determined.

\subsection{The out-of-pipe speed of gangue particles}

The forces encountered by gangue particles in the feeding pipe included the gravity, buoyancy, additional mass force, air bonding resistance, and etc. Zhang et al. [18] obtained the formula of the speed of gangue particles in the feeding pipe, as follows:

$$
u=f+\frac{\sqrt{c} \tan \left[\frac{\sqrt{b} \sqrt{c} t}{a}-\arctan \left(\frac{\sqrt{b} f}{\sqrt{c}}\right)\right]}{\sqrt{b}}
$$

where $a=\rho_{p} \frac{\pi D^{3}}{6}, b=\frac{\pi D^{3}}{8} \rho_{f} C_{D}, c=\rho_{p} \frac{\pi D^{3}}{6} g$ and $f=u_{f}$

Where $D$ is the gangue particle size, $\mathrm{mm} ; \rho_{p}$ is the gangue density, $2500 \mathrm{~kg} / \mathrm{m}^{3} ; g$ is the acceleration of gravity, 9.8/ $\mathrm{ms}^{-2} ; C_{D}$ is the additive resistance coefficient and is often taken as $0.44 ; \rho_{f}$ is the air density and taken as $1.205 \mathrm{Kg} / \mathrm{m}^{3}$; and $u_{f}$ is the air velocity in the feeding pipe, $2 \mathrm{~m} / \mathrm{s}$.

The gangue particle size $D$ was generally between 20 $\mathrm{mm}$ and $100 \mathrm{~mm}$. $D$ of $20,40,60,80$ and $100 \mathrm{~mm}$ were taken and substituted into formula (1) to analyze the influence laws of gangue particle sizes on out-of-pipe rate of gangue particles. after a period of acceleration, the gangue particles reached peak at constant speed through the feeding pipe. When the peak was reached, the impact load of gangue particles on the suspended buffer was the largest. For the conservative estimation, the speed when the peak was reached was taken as the out-of- pipe speed. 
$d v=0$, then

$$
1-\left\{\tan \left[\frac{\sqrt{b} \sqrt{c} t}{a}-\arctan \left(\frac{\sqrt{b} f}{\sqrt{c}}\right)\right]\right\}^{2}=0
$$

Substituting $D$ of 20, 40, 60, 80 and $100 \mathrm{~mm}$ into formula (2), the values of $t$ were 8.6,12.1, 14.8, 17.1 and 19.0 s. Substituting $t$ into formula (1), the values of $v$ were 33.0, 47.6, 58.7, 68.1and $76.4 \mathrm{~m} / \mathrm{s}$, respectively.

\subsection{The numerical simulation schemes}

To analyze influence laws of gangue particle size and gangue feeding rate on the spring's vertical displacement, two numerical simulation schemes were proposed. In scheme I, the gangue feeding rate was $500 t / h$. The gangue particle size was between $20 \mathrm{~mm}$ and $100 \mathrm{~mm}$ and increased every $20 \mathrm{~mm}$. The influence laws of gangue particle size on spring's vertical displacement were studied. In scheme II, the gangue particle size was $60 \mathrm{~mm}$. The feeding rate was 100 700t/h and increased every $200 t / h$. The influence laws of gangue feeding rate on the spring's vertical displacement were studied. Table 1 shows the specific schemes.

Table 1: The schemes of impact loads

\begin{tabular}{cccc}
\hline Schemes & $\begin{array}{c}\text { Gangue } \\
\text { particle size } \\
\text { /mm }\end{array}$ & $\begin{array}{c}\text { Gangue } \\
\text { feeding rate } \\
/ \text { th }^{-1}\end{array}$ & $\begin{array}{c}\text { out-of-pipe } \\
\text { speed } / \mathbf{m s}^{-1}\end{array}$ \\
\hline I & 20 & 500 & 33.0 \\
& 40 & & 47.6 \\
& 60 & & 58.7 \\
& 80 & & 68.1 \\
& 100 & & 76.4 \\
\hline II & 60 & 100 & 58.7 \\
& & 300 & \\
& & 500 & \\
& & 700 & \\
\hline
\end{tabular}

\subsection{Model establishment}

The Pro/E 3D modeling software was adopted. The commands such as stretching, rotating and mirroring were used to establish a solid model of the suspended buffer. Then the 3D model was imported into Femap as IGS file. The mesh generation, element selection, boundary conditions and material attributes were carried out in Femap.

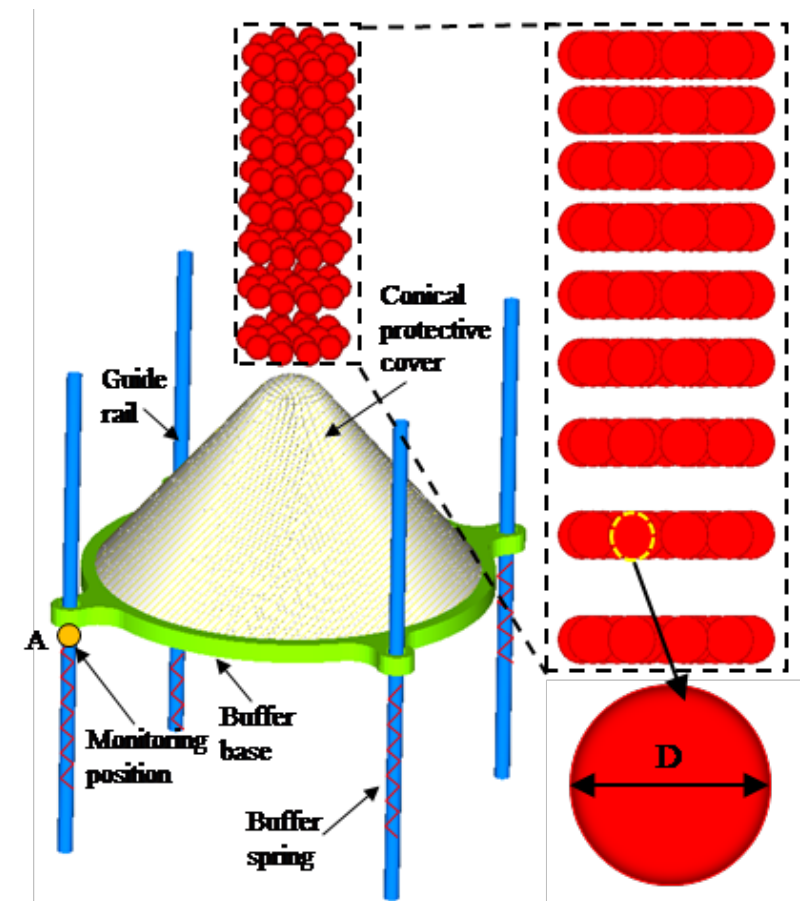

Figure 4: The finite element model of the suspended buffer.

As shown in Figure 4, the conical protection cover and buffer base, buffer spring and guide used the highorder Shell element, DOF spring element and high-order Beam element, respectively [19]. The top of the guild had fixed constraints. The spring and buffer base used the multi-point constraints. The constitutive models of the conical protection cover, the connection between buffer base and guild rails used the bilinear elastoplastic model with isotropic hardening [20]. The conical cover and buffer base were modeled using the bilinear isotropic hardening model [21, 22] with elastic modulus $E_{1}=210 \mathrm{GPa}$, Poisson's ratio $\mu_{1}=0.30$ and tangent modulus $T_{1}=21 \mathrm{GPa}$. The elastic modulus and Poisson's ratio for waste particles are $E_{2}=15.0 \mathrm{GPa}$ and $\mu_{2}=0.27$, respectively. Also, it has a cohesive force $c_{2}$ of $6.2 \mathrm{MPa}$ and an internal friction angle $\varphi_{2}$ of $23^{\circ}$. The stiffness of four buffer springs between the upper and lower limit nuts was $3.8 \times 10^{5} \mathrm{~N} / \mathrm{m}$. The Rayleigh damping [23] was used to reflect the functions of the damping materials, as follows:

$$
C=\alpha M+\beta K
$$

Where $C$ is the damping matrix; $M$ is the mass matrix and $K$ is the stiffness matrix. $A$ and $\beta$ are the proportional coefficients of mass and stiffness damping. Through theoretical analysis and calculation, $\alpha$ is 0.23 and $\beta$ is 0 [24, 25]. So the formula 3 is simplified and reduced to: $\mathrm{C}=0.23 \mathrm{M}$.

In numerical calculation, the mass of individual gangue particles is calculated according to the particle 
size of gangue particles. According to the feeding speed of gangue particles, the quantity of gangue produced in unit time is given in the numerical calculation software. In order to ensure the accuracy and efficiency of numerical simulation, the method of automatic incremental step and arc length is adopted.

The vertical displacement could reflect the vibration characteristics of the buffer spring and provides a basis for safety check and service life prediction. It is therefore necessary to get the change laws of vertical displacement with time and analyze the influence laws of gangue particle size and gangue feeding rate on the spring's vertical displacement. As shown in Figure 4, the vertical displacements at A point were extracted to analyze the influence laws of gangue particle size and gangue feeding rate on the vertical displacement.

\subsection{Parameters calibration for gangues}

In this model, the material properties for conical cover, buffer base, and guide rails were obtained from experimental measurements. However, as gangues were simplified as spheres, the direct use of their properties measured in a lab would inevitably lead to simulation error. It was, therefore, necessary to calibrate the material properties for gangues. This was achieved by permanently adjusting its elastic modulus $E_{2}$, Poisson's ratio $\mu_{2}$, cohesive force $c_{2}$ and internal friction angle $\varphi_{2}$, such that the vertical displacements of the springs in simulation agrees well with that of the field measurements.

\subsubsection{Obtaining gangues}

Gangues with certain diameter must be obtained to calibrate their material parameters. This was achieved using the multistage vibrating screening as shown in Figure 5, which screened out gangues with an approximate diameter of $40 \mathrm{~mm}$. The screened gangues were then fed into the feeding pipe. After coming out from the pipe, gangues collided with the suspended buffer.

\subsubsection{Parameters calibration}

Monitoring the vertical displacements of buffer springs is relatively simple. Therefore, a YWD-80 displacement sensor was installed for the real-time monitoring of its vertical displacement. The maximum data acquisition frequency of this device can reach up to $100 \mathrm{~Hz}$. The device was fixed

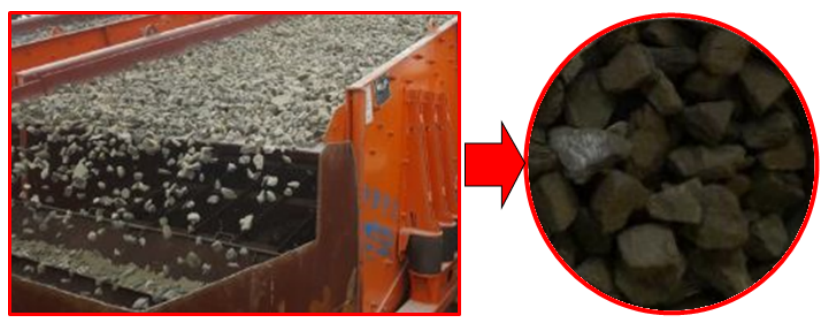

Figure 5: Screening process of gangues.

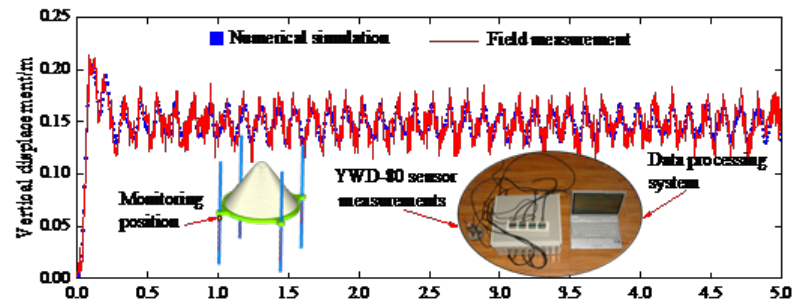

Figure 6: Vertical displacement of the spring in numerical simulation and field measurement.

near the spacing hole. The monitoring time was $5 \mathrm{~s}$, during which the data were obtained and stored.

The vertical displacement of the buffer springs was obtained by the YWD-80 displacement sensor and the data processing system. By permanent adjustment of the parameters for gangues, the vertical displacement in the numerical simulation was converged to that of the field measurement, as shown in Figure 6. The resulting gangue parameters were $E_{2}=16.1 \mathrm{GPa}, \mu_{2}=0.28, c_{2}=5.6 \mathrm{MPa}$ and $\varphi_{2}=22^{\circ}$.

Figure 6 shows that for $D=40 \mathrm{~mm}$, vertical displacement peaks of the springs in numerical simulation and field measurements were $0.214 \mathrm{~m}$ and $0.205 \mathrm{~m}$, respectively, with the corresponding vibration periods of 0.169 $\mathrm{s}$ and $0.173 \mathrm{~s}$. Both the magnitude and trend of the vertical displacement agreed well with the field measurement, which to some extent verified the appropriate selections of gangue parameters.

In order to objectively and accurately analyze the coincidence between field measurement and numerical simulation, hypothesis testing was carried out. During the present study, the Pair-samples $t$ test in Origin software is used. The results show that $P_{-}$vaule $=0.723>0.05$. Therefore, there is no obvious difference between the two groups of data, which proves the reliability and accuracy of numerical simulation. 


\subsection{The analysis of buffer spring's vertical displacement}

\subsubsection{Gangue particle size}

The gangue particle sizes are usually relatively large during the roadway driving and protection layer mining and have large impacts on buffer spring, so they are required to be crushed to a certain size. The size of the crushed gangue particles directly determines the crushing process and crushing costs. The smaller the particle size, the more complicated the process and the higher the costs. However, the smaller the gangue particle size, the lower the speed out of the feeding pipe. At this time, the impacts of the gangues on the buffer are smaller. The spring has higher level of safety and longer service life. Therefore, it is of great significance to determine the critical crushed particle size. As shown in Figure 7, the vertical displacements in scheme I were arranged to analyze the influence laws of the gangue particle size on vertical displacement of suspended spring.

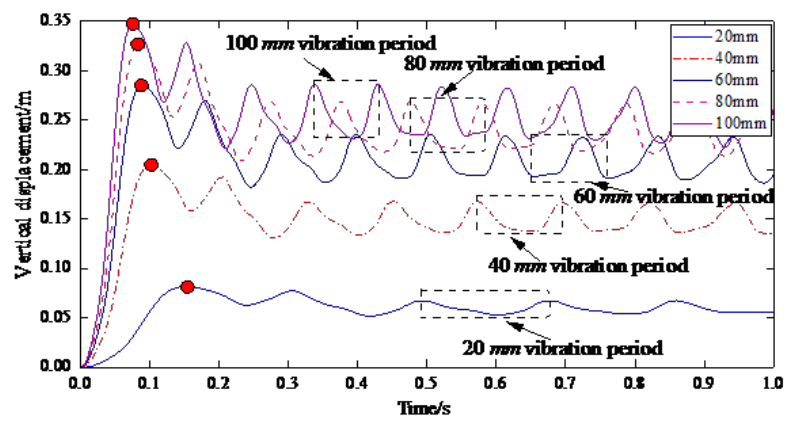

Figure 7: Spring displacement response with different gangue particle sizes.

In Figure 7, the vertical displacement of the buffer spring rapidly increased to the peak after the impacts of the gangues on the suspended buffer. When the gangue particle sizes were $20,40,60,80$ and $100 \mathrm{~mm}$, the vertical displacements reached the peak at $0.151,0.122,0.102$, 0.090 and $0.085 \mathrm{~s}$. The corresponding peak values were $0.082,0.205,0.287,0.324$ and $0.348 \mathrm{~m}$. The corresponding peak values of axial pressure $F_{\text {max }}$ were 31.16, 77.90, 109.06, 123.12 and $132.24 \mathrm{kN}$.

Secondly, after reaching the peak value, the buffer spring gradually entered into the periodic vibration. When the gangue particle sizes were $20,40,60,80$ and $100 \mathrm{~mm}$, the vibration periods of the vertical displacement of the buffer spring were $0.258,0.173,0.149,0.138$ and 0.130 s,

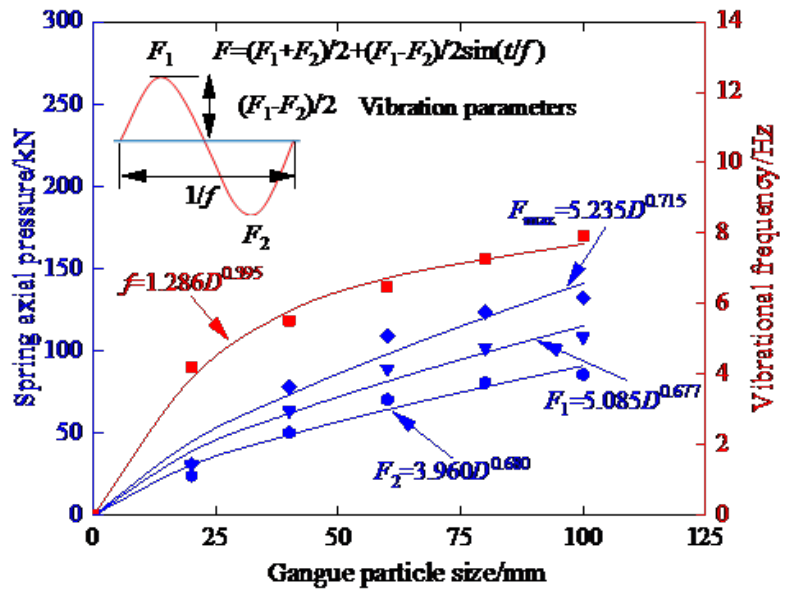

Figure 8: The relations between gangue particle size and the vibration parameters.

respectively. The corresponding frequencies $f$ were 3.870, $5.780,6.721,7.252$ and $7.692 \mathrm{~Hz}$, respectively.

After entering into the periodic vibration, when the gangue particle sizes were $20,40,60,80$ and 100 , the buffer's maximum vertical displacements $W_{1}$ were 0.081 , $0.167,0.234,0.268$ and $0.285 \mathrm{~m}$, respectively, and the minimum vertical displacements $W_{2}$ were $0.063,0.132,0.185$, 0.212 and $0.225 \mathrm{~m}$. The corresponding maximum axial pressures of the spring $F_{1}$ were $30.78,63.46,88.92,101.84$ and $108.30 \mathrm{kN}$, respectively, and the minimum axial pressures $F_{2}$ were $23.94,50.16,70.30,80.56$ and $85.50 \mathrm{kN}$, respectively.

To further analyze the function relationships among the gangue particle size $D$ and buffer spring vibrational frequency $f$, peak axial pressure $F_{\max }$, the maximum axial pressure $F_{1}$, the minimal axial pressure $F_{2}$ within periodic vibration, Figure 8 shows the relations among the gangue particle size $D$ and above-mentioned buffer spring vibration parameters. The Original software was used for data fitting. The results were $f=1.286 D^{0.395}, F_{\max }=$ $5.235 D^{0.715}, F_{1}=5.085 D^{0.677}$ and $F_{2}=3.960 D^{0.680}$.

\subsubsection{Gangue feeding rate}

The gangue feeding rate is directly determined by the gangue's backfilling velocity that is restricted by parameters of the gangue backfilling working face, including the length of the backfilling working face, backfilling height, advance rate of the working face and etc. The change of the above-mentioned parameters has different requirements for the gangue feeding rate. In Figure 9, the vertical displacements of buffer spring in scheme II were arranged. 


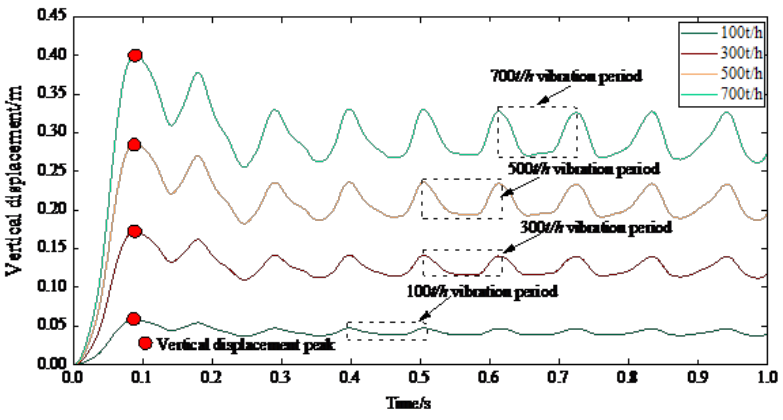

Figure 9: The displacement response of spring vibration with different feeding rates.

The influence laws of the gangue feeding rate on the vertical displacement were analyzed.

The analysis of Figure 9 indicates that the vertical displacements of the spring rapidly increased to the peak after the impacts of gangue particles on the suspended buffer. When the feeding rates were 100, 300, 500 and 700 $\mathrm{t} / \mathrm{h}$, the vertical displacements reached the peak at 0.90 s. The corresponding peak values were $0.057,0.172,0.287$ and $0.401 \mathrm{~m}$. The corresponding axial pressures reached the peak $F_{\max }$, which were $21.66,65.36,109.06$ and 152.38 $\mathrm{kN}$, respectively.

In addition, the spring gradually entered into the periodic vibration when the vertical displacements reached the peak. When the gangue feeding rates were 100, 300, 500 and $700 \mathrm{t} / \mathrm{h}$, the vibration period of spring's vertical displacements was 0.149 and the corresponding frequency was $6.721 \mathrm{~Hz}$. The spring's vibration frequency was irrelevant to the feeding rate. That is, the function relationship between the gangue feeding rate and the vibration frequency could be expressed as $f=6.721$.

(1) After entering into the periodic vibration, with the feeding rates of $100,300,500$ and $700 \mathrm{t} / \mathrm{h}$, the buffer spring's maximum vertical displacements $W_{1}$ were 0.047 , $0.141,0.234$ and $0.331 \mathrm{~m}$. The minimum vertical displacements $W_{2}$ were $0.039,0.117,0.185$ and $0.270 \mathrm{~m}$. The corresponding maximum axial pressures $F_{1}$ were 17.86, 53.58, 88.92 and $125.78 \mathrm{kN}$. The corresponding minimum axial pressures $F_{2}$ were $14.82,44.46,70.30$ and $102.60 \mathrm{kN}$.

The function relations with the gangue feeding rate and buffer spring axial pressure peak $F_{\max }$, the maximum axial pressure $F_{1}$, the minimum axial pressure $F_{2}$ within periodic vibration were analyzed. Figure 10 shows their relations. The Original software was used for data fitting. The results were $F_{\max }=0.218 v, F_{1}=0.179 v$ and $F_{2}=0.145 v$.

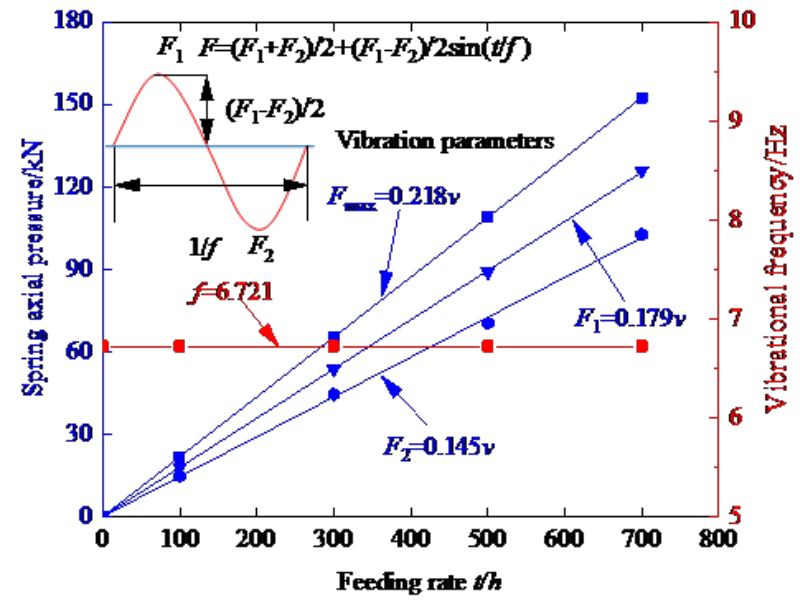

Figure 10: The relations among the feeding rate and vibration parameters.

\section{The safety checks and service life prediction for suspended buffer spring}

\subsection{Safety check}

The safety is the basic parameter of the normal work of the buffer spring, which could be checked by the ultimate axial pressure $P_{n}$. The Eq. (4) is as follows:

$$
P_{n}=\frac{d^{2} \tau_{p}}{2.56 \beta C}
$$

where $d_{1}$ is the material diameter and taken as $0.05 \mathrm{~m} . d_{2}$ is the pitch diameter of the spring and taken as $0.2 \mathrm{~m}$. C is the spring wrap ratio and $C=\frac{d_{2}}{d_{1}}=4 . \beta$ is the spring curvature coefficient, and $\beta=\frac{4 C-1}{4 C-4}+\frac{0.615}{C}=0.14 . \tau_{p}$ is the allowable shearing stress and taken as $740 \mathrm{MPa}$.

Substituting the above parameters into Eq. (4), it could be obtained that $P_{n}=129 \mathrm{kN}$.

In Section 3.5, a power function relation existed between the gangue feeding rate and the maximum spring pressure $F_{\max }$, and the relationship between the gangue feeding rate and the gangue particle size could be expressed in a linear relation. When the gangue particle size was $D$ and feeding rate was $v$, the maximum spring pressure $F_{\max }$ could be expressed as follows by Origin software fitting:

$$
F_{\max }=0.01047 v D^{0.715}
$$

The allowable conditions of the spring material strength could be expressed as follows:

$$
F_{\max }<P_{n}
$$


The following formula could be further obtained.

$$
D<(12321 / v)^{1.399}
$$

\subsection{Service life prediction}

The service life of the buffer spring could directly influence the service life of the suspended buffer. There is a direct relation between the spring's service life and the number of the cyclic vibrations. After numerous experiments, there were certain relationships between the number of spring cyclic load and the shear stress $\tau$ and the tensile strength $\sigma_{b}$ of the spring steel section [26, 27], as shown in Table 2.

Table 2: The number of the spring cyclic load.

\begin{tabular}{ccccc}
\hline Cyclic Number $\boldsymbol{N}$ & $\mathbf{1 0 ^ { 4 }}$ & $\mathbf{1 0}^{5}$ & $\mathbf{1 0}^{\mathbf{6}}$ & $\mathbf{1 0}^{\mathbf{7}}$ \\
\hline$\tau$ & $0.45 \sigma_{b}$ & $0.35 \sigma_{b}$ & $0.33 \sigma_{b}$ & $0.3 \sigma_{b}$ \\
\hline
\end{tabular}

Where $\sigma_{b}$ is the ultimate tensile strength of the spring and taken as $1600 \mathrm{MPa}$.

Under the actions of the axis pressure, the shear stress $\tau$ of the coil spring steel section consisted of two kinds of shear stresses. One was the maximum shear stress $\tau_{1}$ directly produced by the shear force. The other was the maximum shear stress $\tau_{2}$ due to the torque generated by the force.

$$
\begin{gathered}
\tau=\tau_{1}+\tau_{2} \\
\tau_{1}=\frac{16 F_{1}}{3 \pi d^{2}} \\
\tau_{2}=\frac{8 F_{1} D \beta}{\pi d^{3}}
\end{gathered}
$$

Where $F_{1}$ is the maximum axial stress during spring periodic vibration.

Similarly, when the gangue particle size is $D$ and the gangue feeding rate is $v$, the maximum axial stress $F_{1}$ could be expressed as follows:

$$
F_{1}=0.01017 v D^{0.677}
$$

Substituting Eq. (9), (10) and (11) into Eq. (8), the following Eq. (12) was obtained.

$$
\tau=0.06495 v D^{0.677}
$$

According to the ratio relationship of $\tau$ and $\sigma_{b}$ during spring periodic vibration, the number of the spring cyclic loading $N$ was calculated.
Then the Eq. (13) of the service life of the spring was given, as follows:

$$
t=\mathrm{N} /(f T)
$$

Where $f$ is the vibration frequency of the buffer spring and $T$ is the effective feeding time of gangues.

The spring's vibration frequency $f$ had a power function with the gangue particle size $D$, and had nothing to do with the feeding rate $v$. When the gangue particle size was $D$ and the feeding rate was $v$, the buffer spring's vibration frequency was as follows:

$$
f=1.286 D^{0.395}
$$

The service time $t$ of the spring was as follows:

$$
t=\mathrm{N} /\left(1.286 D^{0.395} T\right)
$$

\section{The engineering application}

\subsection{The engineering background}

As shown in Figure 11a, Dongping coal mine is located in Yangquan City, Shanxi Province, China, with recoverable reserves of 4.08 million tons. The serviceable life will be just 3 to 4 years if the annual output is 1.2 million tons. A large number of buildings and farmlands exist in the range of mine field. The coal amounts under the buildings and farmlands reach 73.54 million tons and the recoverable coal amounts reach 63.24 million tons. However, mining problems under buildings and farmlands became the major problems restricting further development of the coal mines in such areas. Therefore, it was decided to recover 15601 working panel at Dongping coal mine using the gangue backfilling technique as shown in Figure 11b.

The underground backfilling techniques determine the gangue feeding rate. When the length of the backfilling working face was $L$, the backfilling height was $H$, the advancing velocity was $V$, the surplus coefficient of gangues is $\eta$, the bulk density of gangues is $\gamma$ and the effective feeding time is $T$, the gangue feeding rate could be expressed as follows:

$$
v=\frac{L H V \eta \gamma}{T}
$$

The specific values of the above-mentioned parameters were given according to on-site backfilling parameters, as shown in Table 3. Substituting the parameters into Eq. (16), the feeding rate of the gangues was $504 t / h$. For the convenience of equipment selection, the feeding rate of gangues $v$ was determined as $500 t / h$. 
Table 3: The parameters for gangue backfilling working face.

\begin{tabular}{cccccc}
\hline $\begin{array}{c}\text { Length of the } \\
\text { working face } \mathrm{L} / \mathrm{m}\end{array}$ & $\begin{array}{c}\text { Backfilling } \\
\text { height } \mathrm{H} / \mathrm{m}\end{array}$ & $\begin{array}{c}\text { Advance velocity } \\
\mathbf{V} / \mathbf{m} / \mathbf{d}\end{array}$ & $\begin{array}{c}\text { Surplus } \\
\text { coefficient of } \\
\text { gangues } \mathbf{S}\end{array}$ & $\begin{array}{c}\text { Bulk density of } \\
\text { gangues } \gamma / \mathbf{t} / \mathrm{m}^{3}\end{array}$ & $\begin{array}{c}\text { Effective feeding } \\
\text { time } \mathrm{T} / \mathrm{s}\end{array}$ \\
\hline 80 & 3.0 & 2.4 & 1.4 & 2.5 & 4 \\
\hline
\end{tabular}

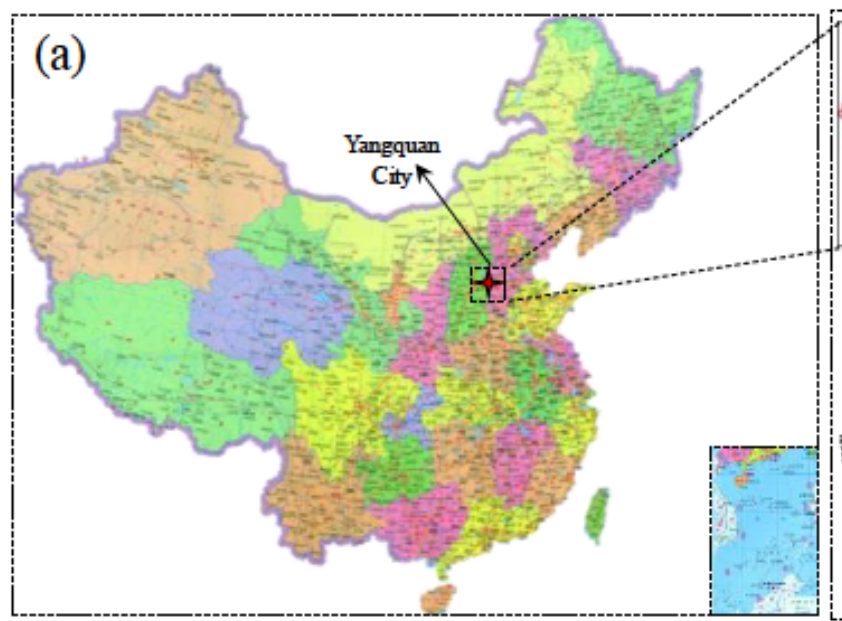

(a) Location of Dongping coal mine

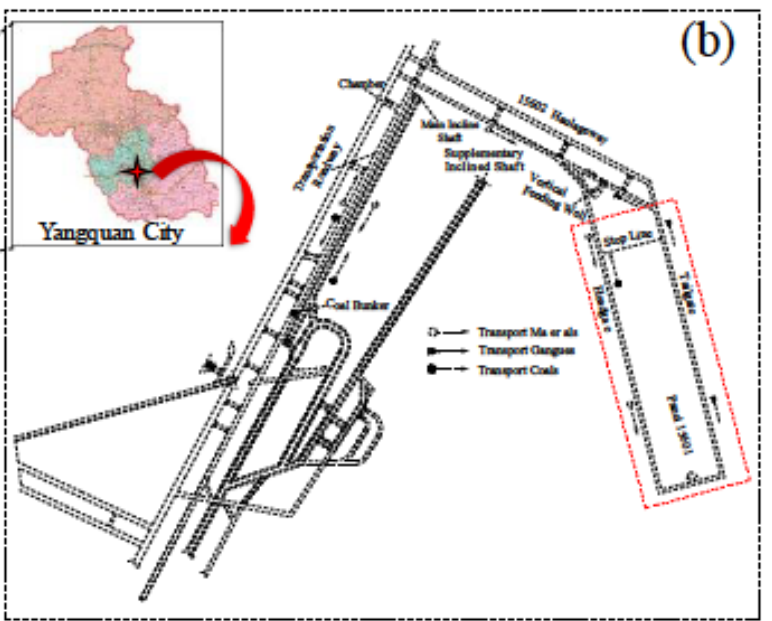

(b)The layout of the working panel

Figure 11: Location of Dongping coal mine and the layout of the working panel.

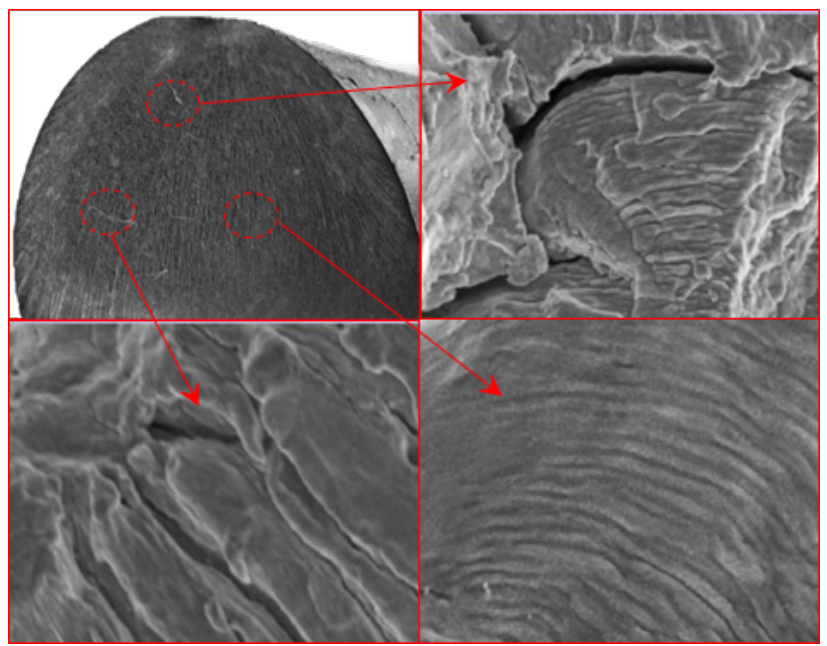

Figure 12: The spring fatigue damage.

\subsection{The safety and service life of the buffer spring}

According to the safety checks, gangue particle size was $D<88.5 \mathrm{~mm}$ by substituting the feeding rate into Eq. (7). Meanwhile, in order to increase the service life of the spring as much as possible, the vibration times of the spring shall be around $1.0 \times 10^{7}$, thus it is required that $\tau<$
$0.3 \sigma_{b}$. Substituting Eq. (12) into Eq. (16), it could obtain that $D<53.4 \mathrm{~mm}$. Based on the safety and service life, the gangue particle shall be $D<53.4 \mathrm{~mm}$. For the convenience of equipment selection, the gangue particle size $D$ was determined as $50 \mathrm{~mm}$.

Substituting gangue particle size into Eq. (15), it could obtain that $t=1658310 \mathrm{~s}$. The gangue feeding time of the feeding system was $4 \mathrm{~h}$ every day, so the service life of the buffer spring was 115 days.

\subsection{The application effects of the spring}

Based on the above researches, the critical crushed particle size of gangue particles was determined to be $50 \mathrm{~mm}$. Initially the loader was used to put the washing gangues into outdoor hopper. Then they would be fed into the screen machine through the conveyer. After screening, the particles less than $50 \mathrm{~mm}$ directly entered belt. The particles more than $50 \mathrm{~mm}$ were crushed again until below $50 \mathrm{~mm}$ and then allowed to enter the belt.

Through 125 days of service, the buffer spring experienced fatigue failure. This was closer to the predicted service life of 115 days and further verified the reliability of the simulation analyses. As shown in Figure 12, the fatigue damage analysis of the spring after use shows that there 
were cracks in spring section and the spring occurred failure and fracture to a certain degree.

\section{Conclusions}

On the basis of results obtained during present study, following conclusions are drawn:

(1) The spring vibration frequency, peak pressure, and the maximum and minimum periodic vibration pressure all presented power functions with the gangue particle $D$. The spring vibration frequency had nothing to do with the gangue feeding rate, while the peak pressure and the maximum and minimum periodic vibration pressure had linear relations with the gangue feeding rate.

(2) According to the ultimate axial pressure and the safety requirement of the spring, the relations between gangue particle size and gangue feeding rate, $D<(12321 / v)^{1.399}$, were obtained. The relationships between the spring's shear stress and tensile strength, $\tau<0.3 \sigma_{b}$, were determined based on the number of spring cyclic road. Then the formula of spring service life, $t=\mathrm{N} /\left(1.286 D^{0.395} T\right)$, was obtained.

(3) Based on the backfilling parameters of the working face of Dongping Coal Mine, the critical gangue particle size and spring's service life were determined as $50 \mathrm{~mm}$ and 115 days, respectively. The failure and damage conditions of the spring were analyzed.

Acknowledgement: This work was supported by the Special Funding Projects of Funded by the Research Fund of the State Key Laboratory of Coal Resources and Safe Mining, CUMT [grant numbers SKLCRSM18KF08]; the National Natural Science Foundation of China (51504127, 51574055). The authors gratefully acknowledge the financial support from the organization.

Funding: Foundation Research Project of Jiangsu Province (BK20160256)

\section{References}

[1] Gong P, Ma ZG, Ni XY, Zhang RR. Floor Heave Mechanism of GobSide Entry Retaining with Fully-Mechanized Backfilling Mining. Energies 2017;10:2085.

[2] Luan HJ, Jiang YJ, Lin HL, Wang YH. A New Thin Seam Backfill Mining Technology and Its Application. Energies 2017;10:2023.
[3] Xie J, Zhu W, Xu J, Wen J, Liu C. A study on the bearing effect of pier column backfilling in the goaf of a thin coal seam. Geosciences Journal 2015;20:361-9.

[4] Cao WH, Wang XF, Li P, Zhang DS, Sun CD, Qin DD. Wide Strip Backfill Mining for Surface Subsidence Control and Its Application in Critical Mining Conditions of a Coal Mine. Sustainability 2018;10:700

[5] Liu Z, Zhnag J, Ju F. Vibration and impact analysis of buffer device of vertical material feeding system in solid backfilling coal mining. Journal of Mining \& Safety Engineering 2014;31:310-4.

[6] Yang PY, Li L, Aubertin M. Stress Ratios in Entire Mine Stopes with Cohesionless Backfill: A Numerical Study. Minerals 2017;7:201.

[7] Wen W-c, Li Y-x, Fu D-m, leee. Study on Impact Energy Absorbing Performance of EPS Buffer Layer of Motorcycle Helmet2013.

[8] Huang CX, Zhu Q, Li CC, Lin W, Xue DJ. Effects of Micronized Fibers on the Cushion Properties of Foam Buffer Package Materials. Bioresources 2014;9:5940-50.

[9] Peng YX, Wang SL, Zhou J, Lei S. Structural design, numerical simulation and control system of a machine tool for stranded wire helical springs. Journal of Manufacturing Systems 2012;31:34-41.

[10] Lee YJ, Park JH, Lee DH, Kang SS. Effect of heat treatment on the hydrogen delayed fracture of high strength spring steel. Journal of Mechanical Science and Technology 2013;27:2991-6.

[11] Jiang C, Zhao GF, Khalili N. On crack propagation in brittle material using the distinct lattice spring model. International Journal of Solids and Structures 2017;118:41-57.

[12] Sencic B, Solic S, Leskovsek V. Fracture toughness-Charpy impact test-Rockwell hardness regression based model for 51CrV4 spring steel. Materials Science and Technology 2014;30:1500-5.

[13] Echtle L, Muller H. Fracture of compression springs. Praktische Metallographie-Practical Metallography 2002;39:473-7.

[14] Chen NZ, Wang G, Soares CG. Palmgren-Miner's rule and fracture mechanics-based inspection planning. Engineering Fracture Mechanics 2011;78:3166-82.

[15] Suhir E, Ghaffarian R, Yi S. Probabilistic Palmgren-Miner rule, with application to solder materials experiencing elastic deformations. Journal of Materials Science-Materials in Electronics 2017;28:2680-5.

[16] Ju F, Li B, Guo S, Xiao M. Dynamic characteristics of gangues during vertical feeding in solid backfill mining: a case study of the Wugou coal mine in China. Environmental Earth Sciences 2016;75:1389

[17] Liu SY, Liu DY, Liu SC. EFFECT OF HEAT TREATMENT ON FATIGUE RESISTANCE OF SPRING STEEL 60Si2CrVAT. Metal Science and Heat Treatment 2010;52:57-60.

[18] Zhang J-x, An B-f, JU F, Jiang H-q, Wu Q. Influence Factors of Solid Material Particles Motion in the Feeding System of Fully Mechanized Coal Mining. Journal of Mining \& Safety Engineering 2012;29:312-6.

[19] Oanta EM, Panait C, Raicu A. Original Data Preprocessor for Femap/Nastran. In: Vladescu M, Tamas R, Cristea I, eds. Advanced Topics in Optoelectronics, Microelectronics, and Nanotechnologies Viii2016.

[20] As'ad R, Demirli K. A bilinear programming model and a modified branch-and-bound algorithm for production planning in steel rolling mills with substitutable demand. International Journal of Production Research 2011;49:3731-49.

[21] Shan G, Zhang H, Wang Y, Zeng C. Finite Element Analysis of Elastic Membrane Coupling Based on MSC.patran. In: Gao J, ed. Advanced Design Technology, Pts 1-32011:1961-5 
[22] Lv Y, Lv GZ, Zhao QL. Development and Application of RVE Library Based on MSC.PATRAN Platform 2008.

[23] Kyriazoglou C, Guild FJ. Finite element prediction of damping of composite GFRP and CFRP laminates - a hybrid formulation vibration damping experiments and Rayleigh damping. Composites Science and Technology 2006;66:487-98.

[24] An FC, Xiao QG, Li S, Li HJ. Mesoscale Modelling of Bond Behavior at FRP-Concrete under Mode II Loading: Effect of Rayleigh Damping. International Journal of Polymer Science 2017;2:1-9.

[25] Min DJ, Park J, Yeon SH, Kim MY. Structural Damping Effects on Dynamic Instability of Subtangentially Loaded and Shear Deformable Beck's Columns. Mathematical Problems in Engineering 2016;3:1-15
[26] Kwon K, Frangopol DM, Soliman M. Probabilistic Fatigue Life Estimation of Steel Bridges by Using a Bilinear S-N Approach. Journal of Bridge Engineering 2012;17:58-70.

[27] Soliman M, Frangopol DM, Kown K. Fatigue Assessment and Service Life Prediction of Existing Steel Bridges by Integrating SHM into a Probabilistic Bilinear S-N Approach. Journal of Structural Engineering 2013;139:1728-40. 